\title{
Radiolabeled Bicyclic Somatostatin-Based Analogs: A Novel Class of Potential Radiotracers for SPECT/PET of Neuroendocrine Tumors
}

\author{
Melpomeni Fani ${ }^{1}$, Andreas Mueller ${ }^{2}$, Maria-Luisa Tamma ${ }^{1}$, Guillaume Nicolas ${ }^{3}$, Hans R. Rink ${ }^{4}$, Renzo Cescato ${ }^{5}$, \\ Jean Claude Reubi ${ }^{5}$, and Helmut R. Maecke ${ }^{1}$ \\ ${ }^{I}$ Division of Radiological Chemistry, University Hospital Basel, Basel, Switzerland; ${ }^{2}$ Fachhochschule Nordwestschweiz, Institute of \\ Chemistry and Bioanalytics, Muttenz, Switzerland; ${ }^{3}$ Institute of Nuclear Medicine, University Hospital Basel, Basel, Switzerland; \\ ${ }^{4}$ Rink Combichem Technologies, Bubendorf, Switzerland; and ${ }^{5}$ Institute of Pathology, University of Bern, Bern, Switzerland
}

\begin{abstract}
A variety of radiolabeled somatostatin analogs have been developed for targeting of somatostatin receptor (sst)-positive tumors. Bicyclic somatostatin-based radiopeptides have not been studied yet. Hypothesizing that the introduction of conformational constraints may lead to receptor subtype selectivity or may help to delineate structural features determining pansomatostatin potency, we developed and evaluated first examples of this new class of potential radiotracers for imaging or therapy of neuroendocrine tumors. Methods: The bicyclic peptides were synthesized by standard solid-phase peptide synthesis. DOTA was coupled to the resin-assembled peptide for labeling with ${ }^{177} \mathrm{Lu}$ and ${ }^{68} \mathrm{Ga}$. Binding affinity and receptor subtype profile were determined using human ssts. $\mathrm{Ca}^{2+}$ flux, internalization, and efflux were studied in human embryonic kidney (HEK)-sst ${ }_{2}$ and

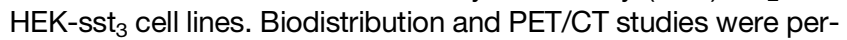
formed in corresponding nude mice models. Results: Some of the new analogs showed high affinity for $\mathbf{s s t}_{2}$ and $\mathrm{sst}_{3}$ and moderate affinity for $s_{1} t_{1}, s_{4}$, and $s_{5} t_{5}$, while exhibiting agonistic properties. The analog AM3, comprising an octreotide ring and a head-to-tail-coupled Arg-diaminobutyric acid(DOTA) cycle, showed the highest receptor affinity and agonist potency. ${ }^{177} \mathrm{Lu}-\mathrm{AM} 3$ showed high and receptor-mediated uptake in vivo in $\mathrm{sst}_{2}$ and $\mathrm{sst}_{3}$ tumors with low background. Kidneys were the only other tissue accumulating radioactivity that could be reduced by a preinjection of lysine. PET/CT studies of ${ }^{68} \mathrm{Ga}-$ $\mathrm{AM} 3$ at $1 \mathrm{~h}$ after injection were characterized by clear localization of the tumor, visualization of the kidneys, and negligible background. Conclusion: The high rigidity of these new bicyclic somatostatin-based radiopeptides led to agonistic ligands with good affinity for all 5 ssts. The pharmacokinetic data of ${ }^{177} \mathrm{Lu} /{ }^{68} \mathrm{Ga}-\mathrm{AM} 3$ make this peptide an excellent candidate as an imaging — and especially as a PET_radiotracer.
\end{abstract}

Key Words: bicyclic somatostatin analogs; somatostatin receptor subtypes; ${ }^{68} \mathrm{Ga}-\mathrm{PET} / \mathrm{CT}$; receptor targeting

J Nucl Med 2010; 51:1771-1779

DOI: 10.2967/jnumed.110.076695

\footnotetext{
Received Feb. 26, 2010; revision accepted Aug. 5, 2010.

For correspondence or reprints contact: Helmut R. Maecke, Clinic for Nuclear Medicine, University Hospital Freiburg, Hugstetterstrasse 55, D-79106 Freiburg, Germany.

E-mail: helmut.maecke@uniklinik-freiburg.de

COPYRIGHT @ 2010 by the Society of Nuclear Medicine, Inc.
}

$\mathbf{R}$ adiolabeled regulatory peptide-based agents have become important radiopharmaceuticals for molecular imaging and targeted radionuclide therapy in nuclear oncology $(1,2)$. Prototypic peptides are derivatives of somatostatin. Five somatostatin receptor subtypes $\left(\mathrm{sst}_{1}-\mathrm{sst}_{5}\right)$ have been identified, all of which were found to be overexpressed on different tumors; the most important one is $\mathrm{sst}_{2}(2-4)$. Current clinical studies indicate that other ssts are also of relevance (5-7). Therefore, chelated pansomatostatin ligands have been developed for the potential targeting of a broader spectrum of tumors $(8-10) .{ }^{68} \mathrm{Ga}$-DOTANOC, with affinity for $\mathrm{sst}_{2,3,5}$, has found its way into the clinic, showing properties superior to ${ }^{111}$ In-pentetreotide (OctreoScan; Covidien) $(6,7) .{ }^{68} \mathrm{Ga}$ is one of the most attractive $\beta^{+}$-emitters because it can be produced from a generator system $(11,12)$.

A neglected group of radiolabeled somatostatin-based peptides are bicyclic peptides. Such peptides were synthesized by the Merck group in the late 1970s, soon after the isolation of the natural hormone (13-15). The rational behind this work was severalfold, namely to understand the bioactive conformation (13) and pharmacophoric amino acid sequence of the natural peptide somatostatin-14 (SRIF14) but also to increase the metabolic stability of the natural peptides (14) by increasing the rigidity. At that time, ssts were not known, and the peptides were studied functionally for their biologic activity.

Veber et al. (13-15) eliminated amino acids in SRIF-14 that were not required for biologic activity and introduced conformational constraints by head-to-tail coupling of a 16atom ring with 7-aminoheptanoic acid (Aha) to the $\mathrm{N}$ - and C-terminally amino acid-deleted octreotide. The bicyclic peptide cyclo(Aha,cyclo(Cys-Phe-D-Trp-Lys-Thr-Cys)) showed higher potency than SRIF-14 and longer duration of biologic activity. In 2001, Falb et al. looked for selectivity toward receptor subtypes (16). They synthesized a backbone and disulfide-bridged bicyclic somatostatin analog. The inner cycle comprised the octreotide sequence, and backbone cyclization was through lactamization via the $\mathrm{N}$ 
and $\mathrm{C}$ terminus of the 2 cysteines. Falb et al. (16) found a high degree of $\mathrm{sst}_{2}$ selectivity, which they explained with the large hydrophobicity of the lactam ring Phe side chains. Intuitively, the introduction of conformational constraints should lead to subtype selectivity. This subtype selectivity was shown in a study by Rivier et al. examining short-chain somatostatin analogs at $\mathrm{sst}_{1}-\mathrm{sst}_{5}$ to identify sterically constrained $\mathrm{sst}_{1}$ selective scaffolds (17). They found a large affinity dependence on the ring size but also highly selective $\mathrm{sst}_{1}$ agonists if they used 4 -( $N$-isopropyl)-aminomethylphenylalanine to replace lysine.

We were interested in the search for metabolically stable pansomatostatin analogs $(9,10)$ and wanted to determine whether bicyclic peptides might form a class of radiopeptides with the required properties. In a first family of peptides, we followed partially the strategy of Veber et al. (13-15) and Falb et al. (16). We kept the octreotide 20-atom sequence as an inner cycle, and instead of using Aha we formed the second 16-atom ring with 2 amino acids, namely Arg and $\gamma$-aminobutyric acid (GABA). GABA could be exchanged with diaminobutyric acid (DAB) for chelator coupling. Arg was assumed to be important for a broad sst subtype profile; this was the conclusion of our studies presented earlier (10).

In this article, we describe the design, pharmacologic and receptor subtype profile, and agonist potency measurements of bicyclic somatostatin-based analogs. In vitro internalization, efflux, pharmacokinetic, and imaging studies in tumor xenografts bearing sst $_{2-}$ and sst $_{3}$-expressing tumors of the 1,4,7,10-tetraazacyclododecane-1,4,7,10-tetraacetic acid (DOTA)-coupled bicyclic analogs labeled with ${ }^{177} \mathrm{Lu}$ and ${ }^{68} \mathrm{Ga}$ were performed. We were intrigued how the introduction of conformational constraints might influence receptor subtype profile and pharmacokinetics of the respective radiopeptides. In addition, we were interested in studying how increased metabolic stability might influence biodistribution, in particular background washout.

\section{MATERIALS AND METHODS}

\section{General}

All commercially obtained chemicals were of analytic grade. Rink-acid resin and 9-fluorenylmethoxycarbonyl amino acids were purchased from NovaBiochem AG and Bachem, respectively. ${ }^{177} \mathrm{LuCl}_{3}$ (specific activity, $740 \mathrm{GBq} / \mathrm{mg}$ ) was from PerkinElmer. The ${ }^{68} \mathrm{Ge} /{ }^{68} \mathrm{Ga}$ generator was obtained from Cyclotron Co. Ltd. The reversed-phase high-performance liquid chromatography (RPHPLC) systems, $\gamma$-counter, and electrospray ionization mass spectrometer were the same as previously reported $(5,8)$. The HPLC gradient was 0-25 $\mathrm{min}, 95 \%-45 \% \mathrm{~A}$ (A, $0.1 \%$ trifluoroacetic acid in water; $\mathrm{B}$, acetonitrile); flow rate, $0.75 \mathrm{~mL} / \mathrm{min}$; and column, Nucleosil 120- $\mathrm{C}_{18}$ (Macherey-Nagel). All reagents used for the functional assays were purchased from common suppliers.

\section{Synthesis of Bicyclic Analogs}

The chemical structures of the investigated analogs are shown in Table 1. The synthesis of the lead peptide HR3005 is depicted in Figure 1. Four new bicyclic analogs based on the lead peptide, 1

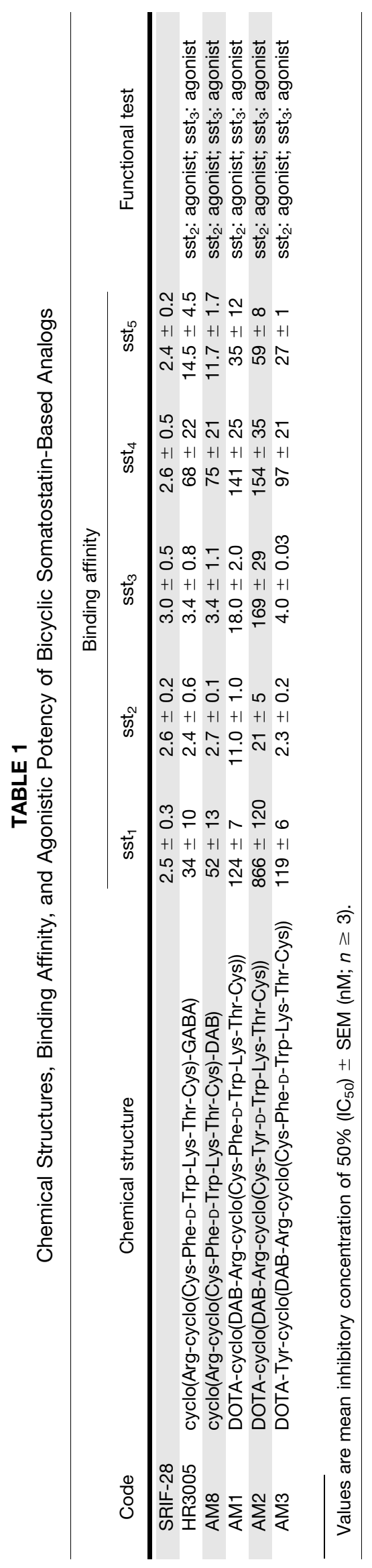




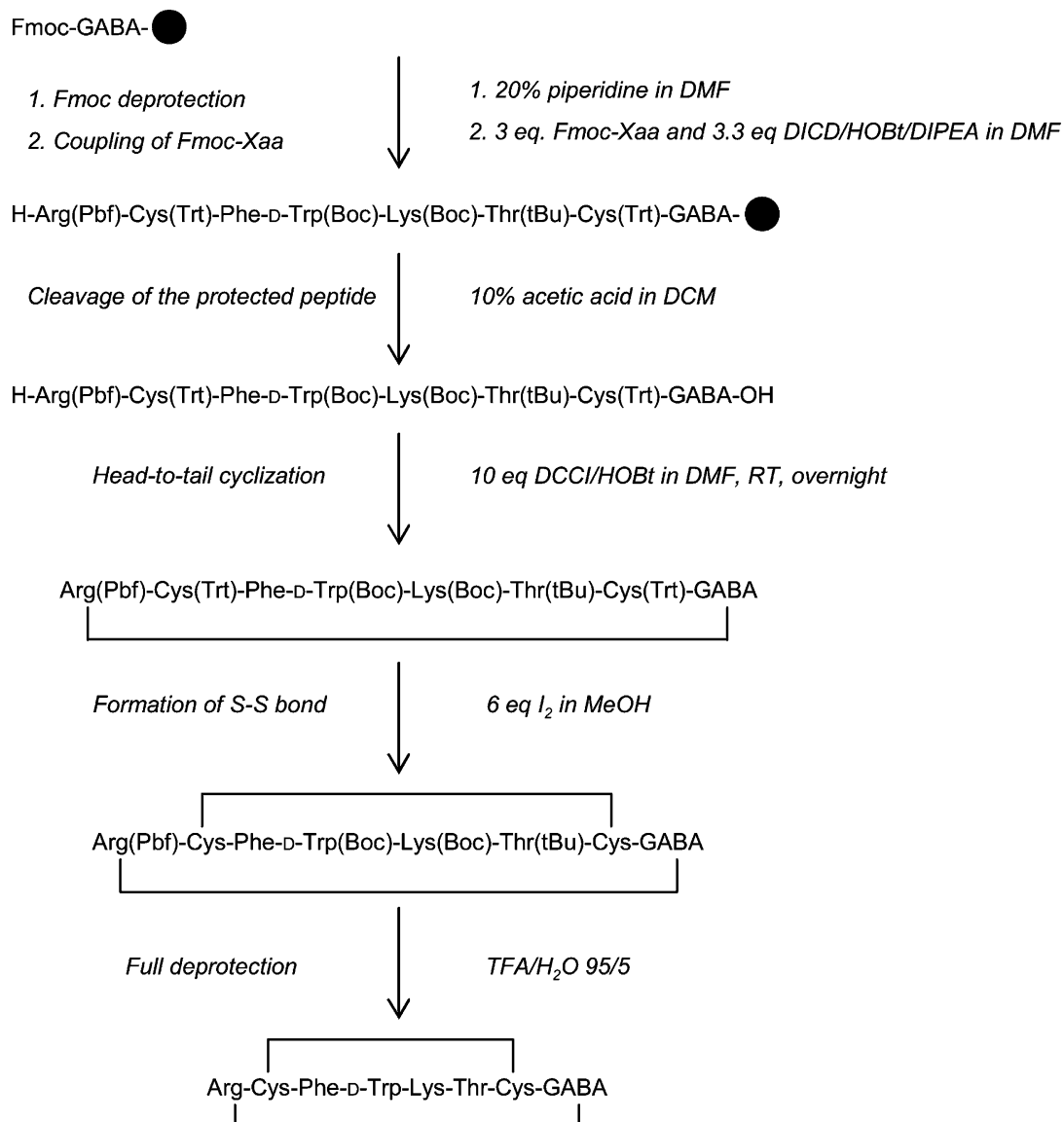

FIGURE 1. Synthesis of HR3005. Standard 9-fluorenylmethoxycarbonyl (Fmoc) solid-phase synthesis was applied to assemble linear peptide using side chainprotected amino acids (Xaa). Boc = tertbutoxycarbonyl; $\mathrm{DCCl}=$ dicyclohexyl-carbodiimide; $\mathrm{DCM}=$ dichloromethane; DICD = diisopropyl-carbodiimide; DIPEA = diisopropyl-ethyl-amine; DMF = dimethylformamide; $\mathrm{HOBt}=$ hydroxybenzotriazole; Pbf $=$ 2,2,4,6,7-pentamethyl-dihydrobenzofuran-5-sulfonyl; RT = room temperature; $\mathrm{tBu}=$ tert-butyl; TFA = trifluoroacetic acid; Trt $=$ trityl. replacing GABA with DAB (AM8) and 3 bearing DOTA (AM1, AM2, and AM3), were synthesized. Details of the synthesis will be published elsewhere. The final products were purified by semipreparative HPLC and characterized by electrospray ionization mass spectrometer and RP-HPLC.

\section{Receptor Autoradiography}

Cell membrane pellets were prepared from human $\mathrm{sst}_{1}$-expressing Chinese hamster ovary cells; $\mathbf{s s t}_{2^{-}}, \mathrm{sst}_{3^{-}}$, and $\mathrm{sst}_{4}$-expressing CCL39 cells; and sst ${ }_{5}$-expressing human embryonic kidney 293 (HEK293) cells and stored at $-80^{\circ} \mathrm{C}$. Receptor autoradiography was performed on $20-\mu$ m-thick membrane pellet sections and quantitated as previously described $(18,19)$.

\section{Immunofluorescence Microscopy}

An immunofluorescence microscopy-based internalization assay for sst $_{2,3}$ was performed with HEK293 cells stably expressing the human $\mathrm{sst}_{2}$ or $\mathrm{sst}_{3}$ using the $\mathrm{sst}_{2}$-specific primary antibody R2-88 (provided by Dr. Agnes Schonbrunn) or the $s_{3}{ }_{3}$-specific primary antibody SS-850 (Gramsch Laboratories), respectively, as previously described (20).

\section{$\mathrm{Ca}^{2+}$ Release Assay}

Intracellular $\mathrm{Ca}^{2+}$ release was measured in HEK-sst $2,3,5$ cells as described previously (19), using the Calcium 3 Assay Kit (Molecular Probes Inc.), according to the manufacturer's instructions. In brief, the cells were seeded $(50,000$ cells/well) in 96-well plates and cultured overnight at $37^{\circ} \mathrm{C}, 5 \% \mathrm{CO}_{2}$. The day of the experiment, cells were washed with assay buffer containing $2.5 \mathrm{mM}$ probenecid and then incubated with $100 \mu \mathrm{L}$ of $\mathrm{Ca}^{2+}$ dye per well for 60 min. Seven different concentrations of HR3005, AM1, AM3, and DOTANOC (used as a reference analog) were dispensed into a reagent source 96-well plate. Cell- and peptide-containing plates were loaded into a FLEX station 3 Microplate Reader (Molecular Devices). Intracellular $\mathrm{Ca}^{2+}$ release was recorded for $130 \mathrm{~s}$, monitoring fluorescence emission at $525 \mathrm{~nm}$ (with excitation wavelength at $=485 \mathrm{~nm}$ ) in the presence of the analogs at concentrations ranging from 2,000 to $0.128 \mathrm{nM}$. Ionomycin and SRIF-14 were used as positive controls at a concentration of 2,000 nM. Baseline measurements were taken for dye-loaded, untreated cells. The data were analyzed by SoftMax Pro software (Molecular Devices).

\section{Preparation of Radiotracers}

${ }^{177} \mathrm{Lu}-\mathrm{AM} 1$ and ${ }^{177} \mathrm{Lu}-\mathrm{AM} 3$ were prepared after incubation of $10 \mu \mathrm{g}$ of each analog with $37-111 \mathrm{MBq}$ of ${ }^{177} \mathrm{LuCl}_{3}$ at $95^{\circ} \mathrm{C}$ for $30 \mathrm{~min}$ in ammonium acetate buffer (0.4 M, pH 5.0). ${ }^{68} \mathrm{Ga}-\mathrm{AM} 3$ was prepared according to the method of Zhernosekov et al. (21), using a different cation exchange column (Strata-XC; Phenomenex) for the purification of the eluate. Quality control was performed by RP-HPLC. The radiotracer solutions were prepared by dilution with $0.9 \% \mathrm{NaCl}$ (saline) containing $0.1 \%$ bovine serum albumin.

\section{Enzymatic Stability in Human Blood and Serum}

${ }^{177} \mathrm{Lu}-\mathrm{AM} 3$ was incubated with fresh human whole blood and serum $\left(30 \mathrm{pmol} / \mathrm{mL}, 37^{\circ} \mathrm{C}\right)$. Blood samples were centrifuged at 1 and $24 \mathrm{~h}$. The erythrocytes were washed with saline and measured 
for radioactivity, and plasma was removed, mixed with acetonitrile (2:3), and centrifuged. Serum samples at $1 \mathrm{~h}$ up to $7 \mathrm{~d}$ were mixed with ethanol (1:2) to precipitate proteins, followed by centrifugation. The supernatants from plasma and serum were analyzed by RP-HPLC to determine the relative amount of intact peptide and possible metabolites.

\section{Radioligand Internalization and Cellular Retention Studies}

The internalization rates of ${ }^{177} \mathrm{Lu}-\mathrm{AM} 1$ and ${ }^{177} \mathrm{Lu}-\mathrm{AM} 3$ and the efflux of ${ }^{177} \mathrm{Lu}-\mathrm{AM} 3$ were studied in HEK-sst ${ }_{2,3}$ cells. The cells were seeded in 6-well plates (0.8-1 million cells per well) and incubated at $37^{\circ} \mathrm{C}, 5 \% \mathrm{CO}_{2}$, overnight. The radiotracer $(2.5 \mathrm{pmol} /$ well) was added to the medium, and the cells were incubated at $37^{\circ} \mathrm{C}$. The internalization was stopped at preselected times $(0.5,1$, 2 , and $4 \mathrm{~h}$ ) by removing the medium. The cells were treated as described previously $(5,8,9)$. Nonspecific internalization was determined using a 1,000-fold excess of DOTANOC. Internalization was expressed as percentage of the applied radioactivity. In efflux studies, ${ }^{177} \mathrm{Lu}-\mathrm{AM} 3$ was allowed to internalize for $2 \mathrm{~h}$ at $37^{\circ} \mathrm{C}$, followed by acid wash $(5,8,9)$. Fresh medium was added, which was then collected at different times $(15,30,60,90,120$, and $240 \mathrm{~min}$ ) for quantification. The recycled fraction was expressed as a percentage of the total internalized amount after $2 \mathrm{~h}$ of incubation at $37^{\circ} \mathrm{C}$.

\section{Animal Biodistribution Studies}

Animals were kept and cared for according to Swiss regulations for animal treatment (approval no. 789). Five-week-old athymic female Swiss nude mice were implanted subcutaneously in the right front leg with $10^{7} \mathrm{HEK}_{-} \mathrm{sst}_{2}$, freshly suspended in sterile phosphate-buffered saline. In a dual-tumor model, the mice were also implanted with $10^{7} \mathrm{HEK}_{-} \mathrm{sst}_{3}$ in the other leg. The tumors were allowed to grow for 14-18 d (tumors weight, 100$150 \mathrm{mg}$ ).

The mice in the dual-tumor model were injected with ${ }^{177} \mathrm{Lu}$ AM3 (100 $\mu \mathrm{L} / 10 \mathrm{pmol} / 0.15 \mathrm{MBq})$ into the tail vein. Nonspecific uptake was determined with a coinjection of a 2,000-fold excess of DOTANOC. The mice (groups of 4-7 animals) were sacrificed under anesthesia at 1,4 , and $24 \mathrm{~h}$ after injection. Additionally, 1 group was preinjected with a $20 \mathrm{mg} / 100 \mu \mathrm{L}$ concentration of lysine in phosphate-buffered saline $10 \mathrm{~min}$ before the injection of the radioligand, to study kidney blocking; the mice were sacrificed at $4 \mathrm{~h}$ after injection.

${ }^{68} \mathrm{Ga}$-AM3 was evaluated in vivo in HEK-sst ${ }_{2}$ tumor-bearing mice injected with ${ }^{68} \mathrm{Ga}-\mathrm{AM} 3(100 \mu \mathrm{L} / 10 \mathrm{pmol} / 0.4 \mathrm{MBq})$ at 1 and $2 \mathrm{~h}$ after injection. Nonspecific uptake and kidney blocking studies were performed.

Organs of interest and blood were collected, rinsed of excess blood, blotted dry, weighed, and counted in a $\gamma$-counter. The results were expressed as percentage injected dose per gram of tissue $(\% \mathrm{ID} / \mathrm{g})$. The total counts injected per animal were determined by extrapolation from counts of an aliquot taken from the injected solution as a standard.

\section{PET/CT Studies}

The mice bearing HEK-sst ${ }_{2}$ tumors were injected with ${ }^{68} \mathrm{Ga}$ AM3 $(100 \mu \mathrm{L} / 10 \mathrm{pmol} / 0.4 \mathrm{MBq})$, including a group preinjected with lysine and a group injected with DOTANOC, as described in the "Animal Biodistribution Studies" section. One hour later, the mice were sacrificed; the bladder was emptied mechanically, and mice were scanned for $60 \mathrm{~min}$ using a routine combined PET/CT scanner (Discovery STE; GE Healthcare). A scout scan $\left(180^{\circ}, 10\right.$ $\mathrm{mA}, 120 \mathrm{kV}$ ) was acquired to establish a protocol for all other scans. CT scans were acquired with minimum slice distance $(16 \times$ $0.625 \mathrm{~mm}$; pitch, 1.375:1) and the highest possible tube current for these settings $(320 \mathrm{~mA}, 120 \mathrm{keV})$. PET emission events were collected in 3-dimensional scanning mode (septa out) over $60 \mathrm{~min}$. Images were corrected for decay of ${ }^{68} \mathrm{Ga}$ and random events and reconstructed using the manufacturer's 3-dimensional ordered-subset expectation maximization algorithm to 47 slices (display field of view, $6.4 \mathrm{~cm}$; matrix, $128 \times 128$; resulting pixel size, $0.5 \mathrm{~mm}$ ), once for each mouse separately in the center of the reconstruction cylinder.

\section{RESULTS}

\section{Synthesis and Radiolabeling}

The chemical structures of the investigated analogs are shown in Table 1. The purity of each analog, determined by RP-HPLC, was $95 \%$ or greater. The overall yields were approximately $30 \%$. Labeling yields for ${ }^{177} \mathrm{Lu}$ and ${ }^{68} \mathrm{Ga}$ were greater than $97 \%$. The specific activities were $17 \mathrm{GBq} / \mu \mathrm{mol}$ for ${ }^{177} \mathrm{Lu}-\mathrm{AM} 1 / \mathrm{AM} 3$ and $35 \mathrm{GBq} / \mu \mathrm{mol}$ for ${ }^{68} \mathrm{Ga}-\mathrm{AM} 3$.

\section{Binding Affinity Profiles and Structure-Activity Relationship}

The binding affinity profiles of the bicyclic somatostatin analogs are listed in Table 1. The lead peptide HR3005 showed high affinity (comparable to SRIF-28) for $\mathrm{sst}_{2}$ and $\mathrm{sst}_{3}$ and moderate affinity for $\mathrm{sst}_{5}, \mathrm{sst}_{1}$, and $\mathrm{sst}_{4}$, conferring almost pansomatostatin potency to this peptide. The replacement of GABA by DAB (AM8) did not change the affinity profile, whereas DOTA-coupling (AM1) led to a 2-fold loss of affinity to $\mathrm{sst}_{1}$ and $\mathrm{sst}_{4}$, a 4-fold loss to $\mathrm{sst}_{2}$, a 5-fold loss to $\mathrm{sst}_{3}$, and a 3 -fold loss to $\mathrm{sst}_{5}$. We reasoned that some affinity increase may be regained by replacing $\mathrm{Phe}^{3}$ (octreotide notation) with $\mathrm{Tyr}^{3}$ (AM2), at least in regard to $\mathrm{sst}_{2}$ affinity. This affinity increase was found in octreotide derivatives but not with these bicyclic peptides, resulting in a further loss of all receptor subtype affinities. By introducing Tyr as a spacer between the DOTA and the peptide (AM3), the affinity to $\mathrm{sst}_{2}$ and $\mathrm{sst}_{3}$ increased significantly, by a factor of 4-5. Slight improvements were also found for $\mathrm{sst}_{4}$ and $\mathrm{sst}_{5}$.

\section{Immunofluorescence-Based Internalization Assay}

An immunofluorescence-based internalization assay using HEK-sst 2 and HEK-sst ${ }_{3}$ was used to determine whether the analogs were able to stimulate receptor internalization and compared their effects with the analog of SRIF-28. Figure 2 illustrates the results of AM3, along with SRIF-28. AM3 applied to the cells for 30 min elicits a pronounced relocation of $\mathrm{sst}_{2}$ (Fig. 2C) and $\mathrm{sst}_{3}$ (Fig. 2F) from the plasma membrane to the cytoplasm, which is detectable by the strong, dotlike perinuclear staining using the R2-88 antibody for $\mathrm{sst}_{2}$ and the SS-850 antibody for $\mathrm{sst}_{3}$. SRIF-28 as a control showed the same stimulating effect (Figs. 2B and 2E). 

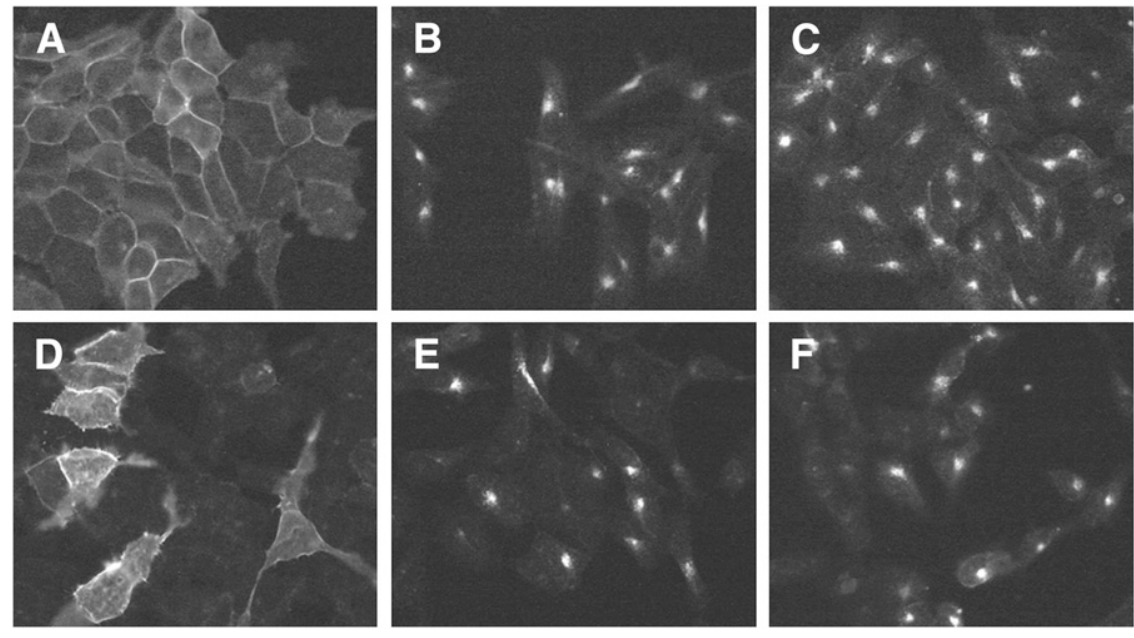

FIGURE 2. sst $_{2}$ and $\mathrm{sst}_{3}$ internalization assay showing agonistic properties of AM3. HEK-sst 2 (A-C) and HEK-sst ${ }_{3}$ (D-F) cells were treated either with vehicle (A and $\mathrm{D}$, negative control) or with $1 \mu \mathrm{M}$ AM3 ( $C$ and $\mathrm{F}$ ). As positive control, cells treated with $1 \mu \mathrm{M}$ SRIF-28 are shown in B and $\mathrm{E}$. After incubation with the peptides, cells were processed for immunocytochemistry as described in "Materials and Methods" section. AM3 exhibits agonistic activity for $\mathrm{sst}_{2}$ and $\mathrm{sst}_{3}$ internalization.

\section{$\mathrm{Ca}^{2+}$ Release Studies}

The bicyclic analogs were tested for their ability to stimulate intracellular $\mathrm{Ca}^{2+}$, a signaling pathway regulated by native somatostatin. On $\mathrm{sst}_{3,5}$, no signal was found with any of the tested analogs, except ionomycin. On sst ${ }_{2}$, a large concentration-dependent increase in intracellular $\mathrm{Ca}^{2+}$ (which corresponds to the fluorescence intensity) was revealed after stimulation with all analogs (Fig. 3). All peptides proved to be agonists, because they stimulated $\mathrm{Ca}^{2+}$ release and displayed high potencies in some cases similar to those of SRIF-14. AM3 yielded a 2-fold higher signal than AM1, HR3005 showed a response similar to that of DOTANOC, and addition of the buffer solution showed no response. The concentration-response curves, analyzed by nonlinear regression curve fitting, are shown in Figure 3B. The agonist-elicited response is quantified in terms of the half maximal effective concentration $\left(\mathrm{EC}_{50}\right)$ values $(\mathrm{nM})$ derived from this fit, calculated as $21.5 \pm 3.5$, $32.2 \pm 8.5,39.6 \pm 12.7$, and $60.0 \pm 9.9$ for AM3, DOTANOC, HR3005, and AM1, respectively.

\section{Enzymatic Stability in Human Blood and Serum}

${ }^{177} \mathrm{Lu}-\mathrm{AM} 3$ was extremely stable in human blood and serum at $37^{\circ} \mathrm{C}$. The erythrocytes isolated from whole blood contained less than $0.1 \%$ of the corresponding activity measured for the same blood volume. No metabolites were observed by HPLC analysis in plasma and serum after $24 \mathrm{~h}$ and $7 \mathrm{~d}$, respectively, for which the only peak in the radiochromatograph observed was the one corresponding to ${ }^{177} \mathrm{Lu}-\mathrm{AM} 3$.

\section{Radioligand Internalization and Cellular Retention Studies}

Figure 4A displays the internalization kinetics of ${ }^{177} \mathrm{Lu}-$ $\mathrm{AM} 1$ and ${ }^{177} \mathrm{Lu}-\mathrm{AM} 3$. In HEK-sst $2,10.5 \pm 1.2 \%$ of totally added ${ }^{177} \mathrm{Lu}-\mathrm{AM} 3$ was internalized at $4 \mathrm{~h}$ and in HEK-sst ${ }_{3}$ $15.3 \pm 2.3 \%$. The corresponding values of ${ }^{177} \mathrm{Lu}-\mathrm{AM} 1$ were less than $3 \% .{ }^{177} \mathrm{Lu}-\mathrm{AM} 3$ showed a lower internalization rate than the reference molecule ${ }^{177} \mathrm{Lu}$-DOTATOC $\left(23.8 \pm 1.6 \%\right.$ in HEK-sst $\left.{ }_{2}\right)$. Nonspecific internalization was less than $1 \%$ (data not shown), demonstrating the receptormediated internalization.

Cellular retention of ${ }^{177} \mathrm{Lu}-\mathrm{AM} 3$ in both HEK-sst ${ }_{2}$ and - sst $_{3}$ cell lines is illustrated in Figure 4B. In both cases, ${ }^{177} \mathrm{Lu}-\mathrm{AM} 3$ seems to reach a plateau after $4 \mathrm{~h}$. The efflux

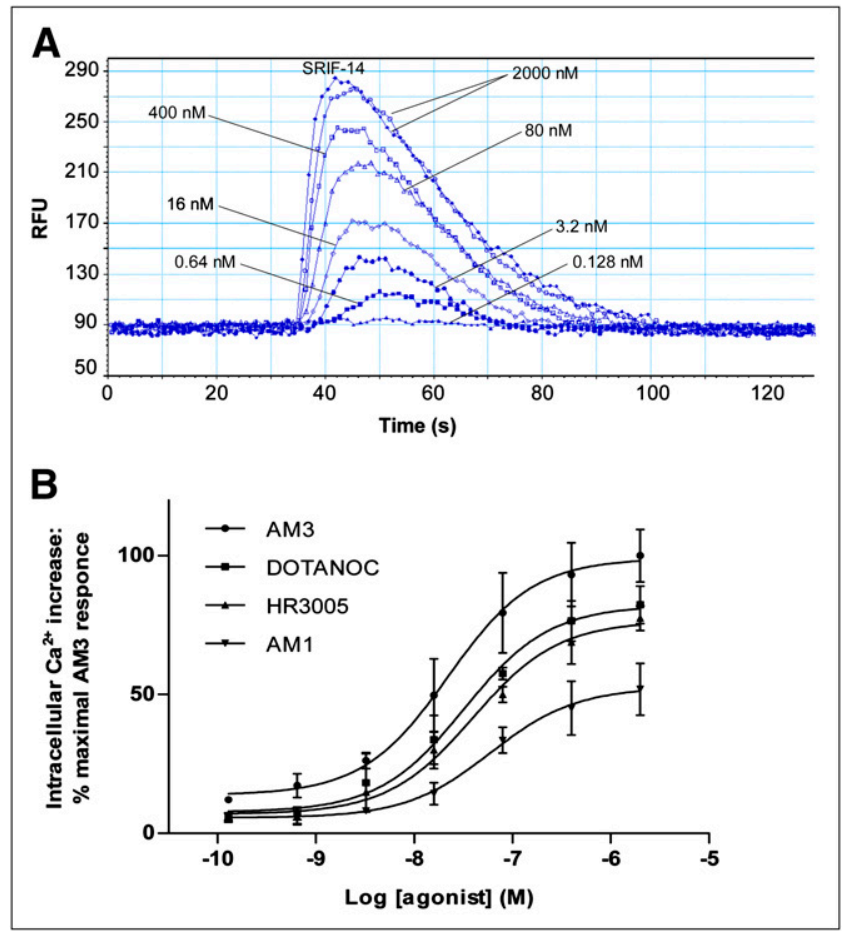

FIGURE 3. Effect of somatostatin analogs on intracellular $\mathrm{Ca}^{2+}$ corresponding to fluorescence intensity. (A) Time course response of intracellular $\mathrm{Ca}^{2+}$ in HEK-sst ${ }_{2}$ cells loaded with $\mathrm{Ca}^{2+}$ dye and activated with indicated concentrations of AM3 and 2,000 nM SRIF-14. Data show representative experiment, typical of 3 experiments performed for each analog. (B) Concentration-response curves of intracellular $\mathrm{Ca}^{2+}$ in HEK-sst ${ }_{2}$ cells for all analogs. Results are expressed as percentage of maximal AM3 response (=100\%) and represent mean \pm SEM of all experiments $(n=3)$. RFU $=$ relative fluorescence unit. 


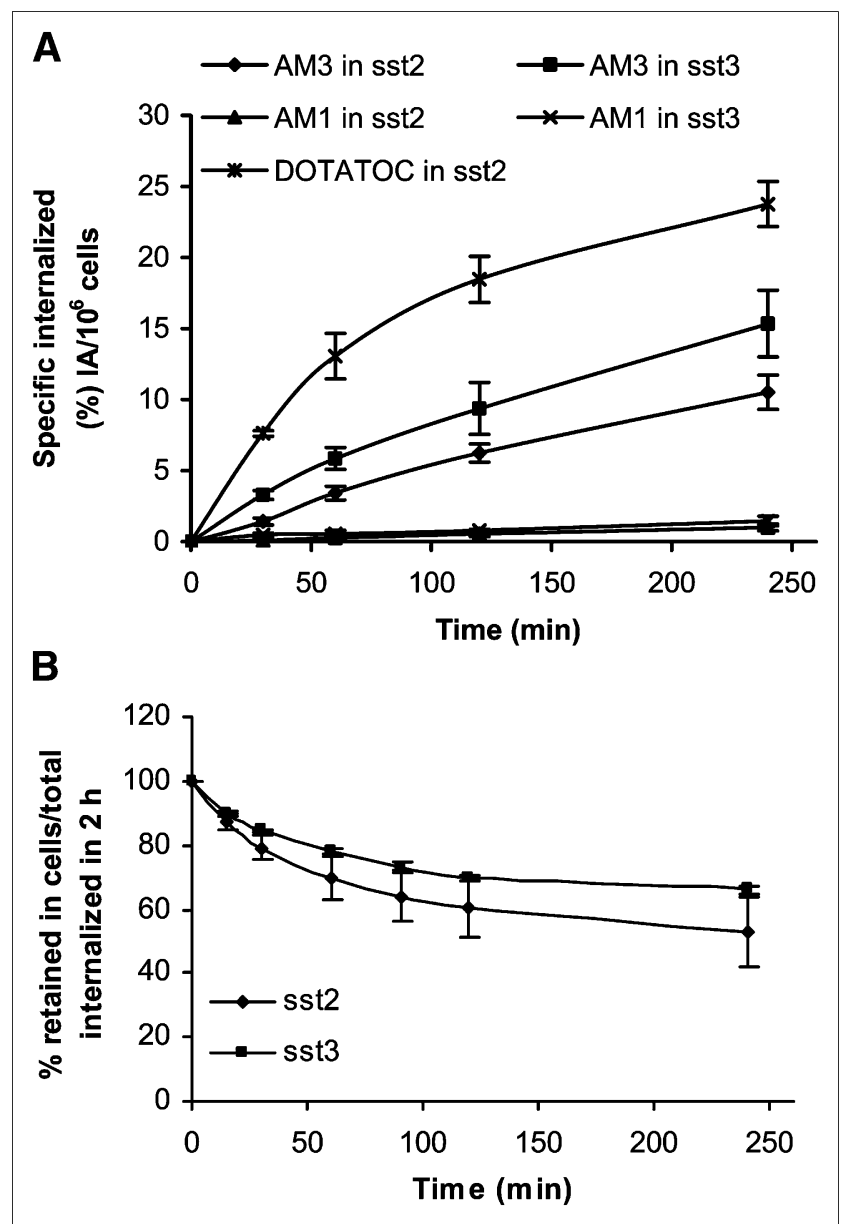

FIGURE 4. (A) Internalization rate of ${ }^{177} \mathrm{Lu}-\mathrm{AM} 1$ and ${ }^{177} \mathrm{Lu}-\mathrm{AM} 3$ into HEK-sst ${ }_{2}$ and $-\mathrm{sst}_{3}$ cells, within $4 \mathrm{~h}$ at $37^{\circ} \mathrm{C}$, expressed as specific internalization, with bars representing \pm SD. ${ }^{177}$ Lu-DOTATOC was used as reference molecule. (B) Cellular radioactivity retention (efflux) of ${ }^{177}$ Lu-AM3 in $\mathrm{HEK}^{-\mathrm{sst}_{2}}$ and - sst $_{3}$ cells over time, expressed as percentage remaining in cells from total amount internalized $(100 \%)$ at $2 \mathrm{~h}$ after incubation at $37^{\circ} \mathrm{C}$, with bars representing \pm SD. Data results are from 2 or 3 independent experiments, with triplicates in each experiment.

of ${ }^{177} \mathrm{Lu}-\mathrm{AM} 3$ was found to be somewhat faster in HEKsst $_{2}$ than in HEK-sst ${ }_{3}$. Within $4 \mathrm{~h}, 45 \%-50 \%$ of ${ }^{177} \mathrm{Lu}-\mathrm{AM} 3$ was released from HEK-sst ${ }_{2}$, whereas only about $35 \%$ was released from $\mathrm{HEK}_{-} \mathrm{sst}_{3}$.

\section{Biodistribution Studies}

The biodistribution profile of ${ }^{177} \mathrm{Lu}-\mathrm{AM} 3$ evaluated in nude mice bearing concomitantly $\mathrm{sst}_{2}$ and $\mathrm{sst}_{3}$ tumors showed fast blood clearance (only $0.01 \% \mathrm{ID} / \mathrm{g}$ was left at $4 \mathrm{~h}$ after injection), fast nontarget clearance, and high receptor-mediated uptake in the tumors; the kidneys were the only other tissue accumulating radioactivity. The results are summarized in Tables 2 and 3. At $1 \mathrm{~h}$ after injection, both tumors accumulated the highest $\% \mathrm{ID} / \mathrm{g}$, with the $\mathrm{sst}_{3}$ tumor exhibiting slightly higher uptake than the $s t_{2}$ tumor. Four hours after injection, about $60 \%$ of the initially accumulated radioactivity remained in both tumors, and less than $30 \%$ was tumor-bound $24 \mathrm{~h}$ later. Blocking experiments with DOTANOC (high $\mathrm{sst}_{2,3,5}$ affinity) confirmed the specific and receptor-mediated uptake. The kidney uptake was not affected by the blocking agents, indicating that this uptake is not receptor-mediated. The tumor-tokidney ratio was greater than 1 , but the slower washout from the kidneys resulted in decreasing tumor-to-kidneys ratios with time ( $\mathrm{sst}_{2} / \mathrm{sst}_{3}$-to-kidney, $1.3 / 1.6$ at $1 \mathrm{~h}$ after injection and 0.8/1.2 at $24 \mathrm{~h}$ after injection). In the application of radiopeptides for targeted radionuclide therapy, the kidneys are dose-limiting (22). In an attempt to improve the tumor-to-kidney ratio by reducing the concentration of the radioactivity in this tissue, we preinjected lysine, which caused an approximately 50\% reduction with no significant impact on the tumor uptake.

The biodistribution profile of ${ }^{68} \mathrm{Ga}-\mathrm{AM} 3$ at early times (Fig. 5) is similar to that of ${ }^{177} \mathrm{Lu}-\mathrm{AM} 3$. The values were on the same level for the sst $_{2}$ tumor uptake (11.92 \pm $1.22 \% \mathrm{ID} / \mathrm{g}$ for ${ }^{68} \mathrm{Ga}$ and $10.37 \pm 0.76 \% \mathrm{ID} / \mathrm{g}$ for $\left.{ }^{177} \mathrm{Lu}\right), 1 \mathrm{~h}$ after injection, and for the tumor-to-kidney ratio (1.2 for ${ }^{68} \mathrm{Ga}$ and 1.3 for ${ }^{177} \mathrm{Lu}$ ). In some organs of interest, such as the liver and blood, slightly higher values were observed with ${ }^{68} \mathrm{Ga}$ than with ${ }^{177} \mathrm{Lu}$, but the tumorto-tissue ratios were also high for ${ }^{68} \mathrm{Ga}-\mathrm{AM} 3$. A reduction of kidney uptake by $50 \%$ without any influence on the tumor uptake by preinjection of lysine was also confirmed, resulting in a significant improvement of tumor-to-kidney ratio from 1.2 to 2.1. Blocking experiments using DOTANOC proved the specific and receptor-mediated tumor uptake.

\section{PET/CT Images Studies}

${ }^{68} \mathrm{Ga}$-AM3 was evaluated in nude mice bearing sst $_{2}$ tumors at $1 \mathrm{~h}$ after injection using PET/CT (Fig. 6). The images showed clearly the high tumor and kidney uptake but negligible background. Preinjection of lysine resulted in a significant reduction of the kidney uptake. The specific uptake of ${ }^{68} \mathrm{Ga}-\mathrm{AM} 3$ was also confirmed using DOTANOC as a blocking agent, with which only the kidneys were visualized. The imaging studies confirmed the biodistribution data.

\section{DISCUSSION}

Radiolabeled analogs of somatostatin are being increasingly used to diagnose and treat patients with sst-positive tumors. A variety of octapeptides have been synthesized over the years to improve receptor affinity, receptor subtype profile, pharmacokinetics, and agonist and antagonist properties. Surprisingly, bicyclic somatostatin-based radiopeptides were overlooked. They were studied as cold peptides by Veber et al. (13-15), mainly to increase the metabolic stability but also to better understand the structural parameters necessary for functional activity. Later, Rivier et al. and the Peptor group along with Falb et al. used this strategy to introduce conformational constraints for sst subtype selectivity $(16,17)$. 
TABLE 2

Biodistribution Results for ${ }^{177}$ Lu-AM3 in Nude Mice Bearing HEK-sst ${ }_{2}$ and HEK-sst Tumors $_{3}$

\begin{tabular}{|c|c|c|c|c|c|}
\hline \multirow[b]{2}{*}{ Organ } & \multicolumn{5}{|c|}{ Biodistribution (h) } \\
\hline & 1 & 4 & 4 , tumor blocking ${ }^{\star}$ & 4, kidney blocking ${ }^{\dagger}$ & 24 \\
\hline Blood & $0.28 \pm 0.20$ & $0.01 \pm 0.00$ & $0.01 \pm 0.01$ & $0.02 \pm 0.01$ & $0.01 \pm 0.01$ \\
\hline Heart & $0.15 \pm 0.03$ & $0.01 \pm 0.01$ & $0.02 \pm 0.01$ & $0.02 \pm 0.01$ & $0.02 \pm 0.01$ \\
\hline Liver & $0.70 \pm 0.05$ & $0.48 \pm 0.08$ & $0.52 \pm 0.10$ & $0.46 \pm 0.08$ & $0.35 \pm 0.10$ \\
\hline Spleen & $0.24 \pm 0.06$ & $0.11 \pm 0.01$ & $0.12 \pm 0.04$ & $0.12 \pm 0.02$ & $0.10 \pm 0.04$ \\
\hline Lung & $0.64 \pm 0.07$ & $0.16 \pm 0.02$ & $0.16 \pm 0.06$ & $0.13 \pm 0.02$ & $0.09 \pm 0.06$ \\
\hline Kidney & $7.81 \pm 0.24$ & $5.09 \pm 1.10$ & $5.66 \pm 0.45$ & $2.61 \pm 0.59$ & $3.00 \pm 0.45$ \\
\hline Stomach & $0.51 \pm 0.04$ & $0.21 \pm 0.02$ & $0.05 \pm 0.03$ & $0.18 \pm 0.05$ & $0.11 \pm 0.03$ \\
\hline Intestine & $0.18 \pm 0.02$ & $0.06 \pm 0.03$ & $0.08 \pm 0.02$ & $0.06 \pm 0.01$ & $0.03 \pm 0.02$ \\
\hline Adrenal & $0.21 \pm 0.02$ & $0.02 \pm 0.02$ & $0.15 \pm 0.08$ & $0.18 \pm 0.06$ & $0.07 \pm 0.02$ \\
\hline Pancreas & $0.18 \pm 0.02$ & $0.05 \pm 0.03$ & $0.03 \pm 0.00$ & $0.07 \pm 0.01$ & $0.04 \pm 0.00$ \\
\hline Pituitary & $0.75 \pm 0.15$ & $0.31 \pm 0.06$ & $0.19 \pm 0.06$ & $0.32 \pm 0.17$ & $0.03 \pm 0.06$ \\
\hline Muscle & $0.06 \pm 0.03$ & $0.01 \pm 0.01$ & $0.03 \pm 0.02$ & $0.01 \pm 0.01$ & $0.02 \pm 0.01$ \\
\hline Bone & $0.28 \pm 0.06$ & $0.07 \pm 0.04$ & $0.05 \pm 0.01$ & $0.15 \pm 0.05$ & $0.15 \pm 0.05$ \\
\hline sst $_{2}$ tumor & $10.37 \pm 0.76$ & $6.05 \pm 1.13$ & $1.82 \pm 0.66$ & $4.94 \pm 1.45$ & $2.33 \pm 0.66$ \\
\hline sst $_{3}$ tumor & $12.74 \pm 0.75$ & $7.56 \pm 2.16$ & $0.37 \pm 0.07$ & $6.24 \pm 1.30$ & $3.61 \pm 0.74$ \\
\hline \multicolumn{6}{|c|}{$\begin{array}{l}{ }^{*} \text { Tumor blocking: coinjection of } 2,000 \text {-fold excess of DOTANOC. } \\
{ }^{\dagger} \text { Kidney blocking: } 10-\text { min preinjection of } 20 \mathrm{mg} \text { of lysin/100 } \mu \mathrm{L} \text {. } \\
\text { Data are \%ID/g } \pm \mathrm{SD}, n=4-7 \text {. }\end{array}$} \\
\hline
\end{tabular}

In a first family of peptides, we partially followed the approach of Veber et al. by keeping the 20-atom sequence of the $\mathrm{N}$ - and C-terminally amino acid-deleted octreotide as an inner cycle and by adding a 16-atom ring composed of the 2 amino acids Arg and GABA head-to-tail. This lead peptide showed high affinity for $\mathrm{sst}_{2}$ and $\mathrm{sst}_{3}$ comparable to SRIF-28 and also moderate affinity for $\mathrm{sst}_{1,4,5}$, indicating that the introduced conformational constraints did not result in subtype selectivity; on the contrary, the sst binding profile is broader than the profile of most octapeptides, such as DOTATOC or DOTATATE (18). GABA was exchanged with DAB (AM8), which affords an amino group for coupling of a chelator. Coupling of DOTA resulted in a distinct loss of affinity to all receptor subtypes, an effect that was also seen in octreotide-derived octapeptides but not to the same extent. We assumed that some of the loss to sst $_{2}$ can be recovered by replacing $\mathrm{Phe}^{3}$ for $\mathrm{Tyr}^{3}$ (AM1 vs. AM2), as found in octreotide derivatives, but in this family of peptides the reverse effect was observed. The affinity loss with the introduction of the chelator was almost regained when introducing Tyr as a spacer between DOTA and the peptide (AM3 vs. AM1), indicating that the introduction of spacer molecules may be a means to further improve receptor affinity and subtype profile of this family of peptides.

Both the immunofluorescence-based internalization assays for $\mathrm{sst}_{2,3}$ and the $\mathrm{Ca}^{2+}$ flux for $\mathrm{sst}_{2,3,5}$ showed that the peptides are agonists on $\mathrm{sst}_{2}$ and $\mathrm{sst}_{3}$. A side-by-side comparison of the DOTA-bearing analogs with the lead peptide showed the superiority of AM3 in $\mathrm{Ca}^{2+}$ mobilization.

The internalization kinetics into HEK-sst ${ }_{2}$ of the ${ }^{177} \mathrm{Lu}-$ labeled analogs are time-dependent but relatively slow compared with those of octapeptides such as ${ }^{111} \mathrm{In} /{ }^{177} \mathrm{Lu}-$ DOTATOC, despite the higher affinity of AM3. Also AM1, having the same sst $_{2}$ affinity as DOTATOC, shows low internalization. The internalization into HEK-sst ${ }_{3}$ is somewhat faster than that into HEK-sst ${ }_{2}$, as may be explained by the higher receptor density of HEK-sst ${ }_{3}$ (23). It seems possible that the increased rigidity of the bicyclic peptides is responsible for the lower internalization rates. We have

TABLE 3

Tumor-to-Normal-Tissue Ratios for ${ }^{177}$ Lu-AM3 in Nude Mice Bearing HEK-sst 2 and HEK-sst 3 Tumors

\begin{tabular}{|c|c|c|c|c|}
\hline \multirow[b]{2}{*}{ Tumor-to-normal-tissue ratio } & \multicolumn{4}{|c|}{ Time (h) } \\
\hline & 1 & 4 & 4 , kidney blocking ${ }^{*}$ & 24 \\
\hline sst $_{2} / \mathrm{sst}_{3}$ to blood & $37 / 46$ & $893 / 1,117$ & $289 / 365$ & $388 / 600$ \\
\hline sst $_{2} /$ sst $_{3}$ to kidney & $1.3 / 1.6$ & $1.2 / 1.5$ & $1.9 / 2.4$ & $0.8 / 1.2$ \\
\hline sst $_{2} /$ sst $_{3}$ to liver & $15 / 18$ & $13 / 16$ & $11 / 14$ & $6.7 / 10$ \\
\hline $\mathrm{sst}_{2} / \mathrm{sst}_{3}$ to muscles & $171 / 209$ & $700 / 875$ & $339 / 428$ & $130 / 201$ \\
\hline
\end{tabular}




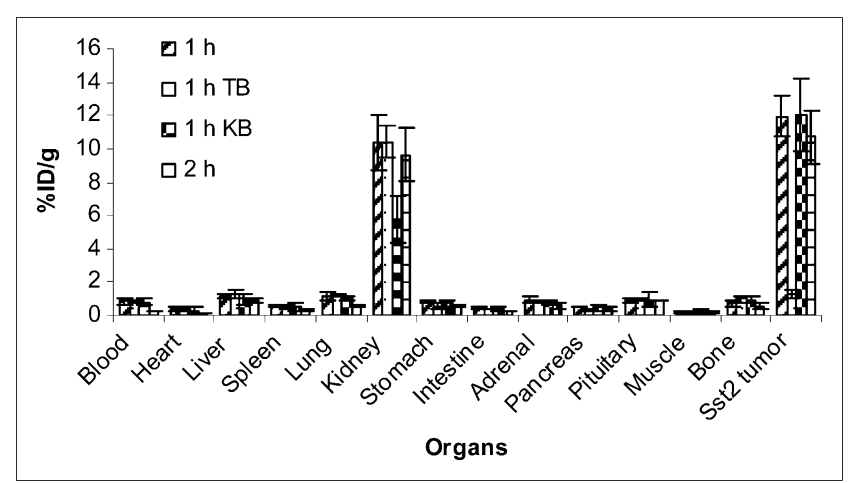

FIGURE 5. Biodistribution and blocking studies (tumor blocking [TB] with 2,000-fold excess of DOTANOC; kidney blocking [KB] with preinjection of $20 \mathrm{mg} / 100 \mu \mathrm{L}$ concentration of lysine) of ${ }^{68} \mathrm{Ga}-\mathrm{AM} 3$ in sst $_{2}$ tumor-bearing mice at 1 and $2 \mathrm{~h}$ after injection. Data are expressed as \%ID/g $\pm \mathrm{SD}(n=4-7)$.

seen earlier that carbocyclic octapeptides having pansomatostatin character internalize in some receptor subtypes but not in others (10). Furthermore, the increased rigidity of the present peptides may also be the reason for the high metabolic stability found for ${ }^{177} \mathrm{Lu}-\mathrm{AM} 3$ in human blood and serum.

The in vivo pharmacokinetic data of ${ }^{177} \mathrm{Lu}-\mathrm{AM} 3$ and ${ }^{68} \mathrm{Ga}-\mathrm{AM} 3$ reflect the internalization and efflux data with respect to somewhat low tumor uptake and fast washoutonly a hypothesis because we do not know the internalization rate in vivo of these radiopeptides. Recently, we demonstrated that in vivo internalization may be a fast process, happening within minutes if potent agonists are being injected into AR4-2J tumor-bearing rats (24).

The pharmacokinetic data are promising in respect to the fast clearance from nontargeted organs, allowing for a high tumor-to-blood and tumor-to-muscle ratio already at $1 \mathrm{~h}$, increasing to around 1,000 at $4 \mathrm{~h}$ for both tissues. The tumor-to-tissue ratios represent important parameters to evaluate the quality of imaging agents. In our case, all organs except the kidneys show low uptake and retention. The kidney uptake of radiometallated peptides is a serious concern; usually the tumor-to-kidney-ratios are less than 1 .
We found higher tumor-to-kidney ratios, which are due to the relatively low kidney uptake considering the 2-plus overall charge of the radiopeptide. We and others found that positive charges increase kidney uptake $(10,25,26)$. Recently, we found a kidney uptake of $58.7 \pm 11.0 \% \mathrm{ID} / \mathrm{g}$ at $4 \mathrm{~h}-$ a value 10 -fold higher than with the present studyin the same tumor model using a pansomatostatin DOTAcoupled peptide with the same amino acid composition (10). This example shows the difficulty in understanding the exact mechanism of kidney uptake and retention (27) and that charge distribution, and possibly the metabolic stability of the peptides, are decisive for kidney uptake. The kidney uptake could be reduced by $50 \%$ by the preinjection of lysine, which is in agreement with what is known from the usual octreotide-based monocyclic radiopeptides (28).

The pharmacokinetics of ${ }^{177} \mathrm{Lu}-\mathrm{AM} 3$ makes AM3 an excellent candidate to be developed into an imaging agent, although we do not know whether a similar rapid washout from sst $_{2}$-positive organs, such as the pancreas, will also occur in humans. AM3 seems to be comparable or even more promising than analogs with similar broad sst binding profiles, such as DOTANOC $(5,8)$. ${ }^{111}$ In-DOTANOC showed similar uptake in sst ${ }_{3}$ tumors $(17.5 \pm 4.3$ and $6.5 \pm$ $0.7 \% \mathrm{ID} / \mathrm{g}$ at 0.5 and $4 \mathrm{~h}$, respectively) in the same tumor model (29) but tumor-to-normal-tissue ratios are superior for ${ }^{177} \mathrm{Lu}$-AM3. Another potent $\mathrm{sst}_{2}$-selective agonist, ${ }^{111} \mathrm{In}$ diethylenetriaminepentaacetic acid-TATE (inhibitory concentration of $50 \%$ (IC50), $1.3 \pm 0.2 \mathrm{nM}$ ), shows higher tumor uptake at $4 \mathrm{~h}(15.8 \pm 3.9 \% \mathrm{ID} / \mathrm{g})(29)$. However, tumor-tonormal-tissue ratios, such as tumor-to-blood and tumor-tomuscles, are superior for ${ }^{177} \mathrm{Lu}-\mathrm{AM} 3$, whereas the tumorto-kidney ratio is similar. The efficient background clearance, most probably due to the high stability of the bicyclic analog and the fact that there is an increased interest in the development of new PET tracers based on the generator-produced ${ }^{68} \mathrm{Ga}$, led us to label this peptide with ${ }^{68} \mathrm{Ga}$ and to evaluate ${ }^{68} \mathrm{Ga}-\mathrm{AM} 3$ in the $\mathrm{sst}_{2}$ tumor model. ${ }^{68} \mathrm{Ga}-$ AM3 showed pharmacokinetics similar to ${ }^{177} \mathrm{Lu}-\mathrm{AM} 3$, clear tumor delineation, and receptor-mediated uptake.

FIGURE 6. PET/CT images of sst $_{2}$ tumorbearing nude mice at $1 \mathrm{~h}$ after injection of ${ }^{68} \mathrm{Ga}-\mathrm{AM} 3$ (A) show clearly high uptake in tumor, accumulation of radioactivity in kidneys, and negligible background. (B) Preinjection of lysine reduces kidney uptake significantly and increases tumor-to-kidney ratio. (C) Coinjection of DOTANOC in excess demonstrates specific receptor-mediated uptake of ${ }^{68} \mathrm{Ga}-\mathrm{AM} 3$.

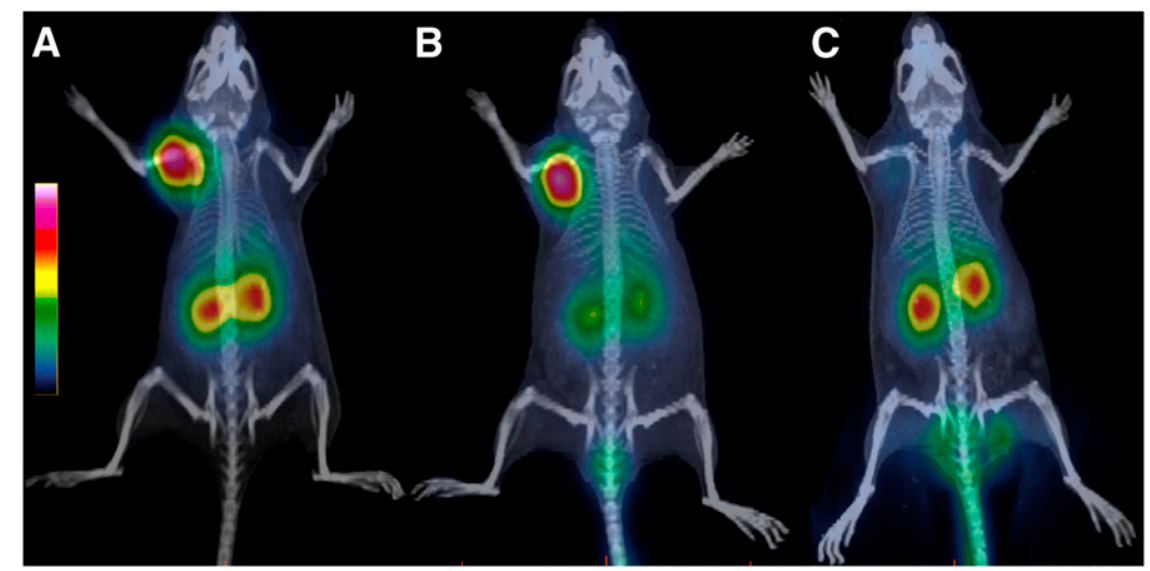


Besides the tumor, only the kidneys were clearly visible on PET/CT images-kidney uptake could be blocked by injecting lysine. On the other hand, in the case of diagnostic radiotracers, compared with therapeutic radiopharmaceuticals, the kidney uptake is not such a serious drawback, especially when PET isotopes with a short half-life are used.

\section{CONCLUSION}

The high rigidity of the family of bicyclic somatostatinbased analogs studied here led to agonistic ligands with almost pansomatostatin properties. This family of radiopeptides appears to constitute another group of radiopeptides, showing the importance of a high internalization capacity for a high and long-lasting tumor uptake. This importance was shown recently in a study of a group of pansomatostatin radioligands (10). Interestingly, this finding does not correlate with the properties of low or noninternalizing antagonists. Why this is the case is not clear yet and needs further study. On the other hand, high-contrast imaging depends not only on high absolute target uptake but also on an efficient background clearance, clearly demonstrated with ${ }^{68} \mathrm{Ga}-\mathrm{AM} 3$. This family of radiopeptides may not be suitable for targeted radionuclide therapy with a long-lived radionuclide such as ${ }^{177} \mathrm{Lu}$ but may be a good candidate for PET/CT studies of sst-expressing tumors.

\section{ACKNOWLEDGMENTS}

We thank Dr. Stephan Schulz for the sst $_{2,3,5}$-transfected HEK cells; Dr. Andreas Bauman, Sibylle Tschumi, and the staff of the Radiological Chemistry and Nuclear Medicine Departments, University Hospital Basel, for their assistance; Novartis Pharma for analytic assistance; and the COST D38 action. This work was supported by the Swiss National Science Foundation (no. 320000-118333).

\section{REFERENCES}

1. Breeman WA, Kwekkeboom DJ, de Blois E, de Jong M, Visser TJ, Krenning EP. Radiolabelled regulatory peptides for imaging and therapy. Anticancer Agents Med Chem. 2007;7:345-357.

2. Reubi JC, Maecke HR. Peptide-based probes for cancer imaging. J Nucl Med. 2008;49:1735-1738.

3. Reubi JC. Peptide receptors as molecular targets for cancer diagnosis and therapy. Endocr Rev. 2003;24:389-427.

4. Lewis JS, Lewis MR, Srinivasan A, Schmidt MA, Wang J, Anderson CJ. Comparison of four ${ }^{64} \mathrm{Cu}$-labeled somatostatin analogues in vitro and in a tumor-bearing rat model: evaluation of new derivatives for positron emission tomography imaging and targeted radiotherapy. J Med Chem. 1999;42:13411347.

5. Antunes P, Ginj M, Zhang H, et al. Are radiogallium-labelled DOTA-conjugated somatostatin analogues superior to those labelled with other radiometals? Eur J Nucl Med Mol Imaging. 2007;34:982-993.
6. Ambrosini V, Tomassetti P, Castellucci P, et al. Comparison between ${ }^{68} \mathrm{Ga}$ DOTA-NOC and ${ }^{18} \mathrm{~F}$-DOPA PET for the detection of gastro-entero-pancreatic and lung neuro-endocrine tumours. Eur J Nucl Med Mol Imaging. 2008; 35:1431-1438.

7. Prasad V, Ambrosini V, Hommann M, Hoersch D, Fanti S, Baum RP. Detection of unknown primary neuroendocrine tumours (CUP-NET) using ${ }^{68} \mathrm{Ga}$-DOTANOC receptor PET/CT. Eur J Nucl Med Mol Imaging. 2010;37:67-77.

8. Wild D, Schmitt JS, Ginj M, et al. DOTA-NOC, a high-affinity ligand of somatostatin receptor subtypes 2, 3 and 5 for labelling with various radiometals. Eur J Nucl Med Mol Imaging. 2003;30:1338-1347.

9. Ginj M, Schmitt JS, Chen J, et al. Design, synthesis, and biological evaluation of somatostatin-based radiopeptides. Chem Biol. 2006;13:1081-1090.

10. Ginj M, Zhang H, Eisenwiener KP, et al. New pansomatostatin ligands and their chelated versions: affinity profile, agonist activity, internalization, and tumor targeting. Clin Cancer Res. 2008;14:2019-2027.

11. Maecke HR, Hofmann M, Haberkorn U. ${ }^{68}$ Ga-labeled peptides in tumor imaging. J Nucl Med. 2005;46(suppl):172S-178S.

12. Fani M, Andre JP, Maecke HR. ${ }^{68} \mathrm{Ga}-\mathrm{PET}$ : a powerful generator-based alternative to cyclotron-based PET radiopharmaceuticals. Contrast Media Mol Imaging. 2008;3:67-77.

13. Veber DF, Holly FW, Paleveda WJ, et al. Conformationally restricted bicyclic analogs of somatostatin. Proc Natl Acad Sci USA. 1978;75:2636-2640.

14. Veber DF, Holly FW, Nutt RF, et al. Highly active cyclic and bicyclic somatostatin analogues of reduced ring size. Nature. 1979;280:512-514.

15. Veber DF, Freidlinger RM, Perlow DS, et al. A potent cyclic hexapeptide analogue of somatostatin. Nature. 1981;292:55-58.

16. Falb E, Salitra Y, Yechezkel T, et al. A bicyclic and hsst2 selective somatostatin analogue: design, synthesis, conformational analysis and binding. Bioorg Med Chem. 2001;9:3255-3264.

17. Rivier JE, Kirby DA, Erchegyi J, et al. Somatostatin receptor 1 selective analogues: 3. Dicyclic peptides. J Med Chem. 2005;48:515-522.

18. Reubi JC, Schar JC, Waser B, et al. Affinity profiles for human somatostatin receptor subtypes SST1-SST5 of somatostatin radiotracers selected for scintigraphic and radiotherapeutic use. Eur J Nucl Med. 2000;27:273-282.

19. Cescato R, Erchegyi J, Waser B, et al. Design and in vitro characterization of highly sst2-selective somatostatin antagonists suitable for radiotargeting. J Med Chem. 2008;51:4030-4037.

20. Cescato R, Schulz S, Waser B, et al. Internalization of sst2, sst3, and sst5 receptors: effects of somatostatin agonists and antagonists. J Nucl Med. 2006;47:502-511.

21. Zhernosekov KP, Filosofov DV, Baum RP, et al. Processing of generatorproduced ${ }^{68} \mathrm{Ga}$ for medical application. J Nucl Med. 2007;48:1741-1748.

22. Rolleman EJ, Melis M, Valkema R, Boerman OC, Krenning EP, de Jong M. Kidney protection during peptide receptor radionuclide therapy with somatostatin analogues. Eur J Nucl Med Mol Imaging. 2010;37:1018-1031.

23. Pfeiffer M, Koch T, Schroder H, et al. Homo- and heterodimerization of somatostatin receptor subtypes. Inactivation of $\mathrm{sst}_{3}$ receptor function by heterodimerization with $\mathrm{sst}_{2 \mathrm{~A}}$. J Biol Chem. 2001;276:14027-14036.

24. Waser B, Tamma ML, Cescato R, Maecke HR, Reubi JC. Highly efficient in vivo agonist-induced internalization of sst 2 receptors in somatostatin target tissues. J Nucl Med. 2009;50:936-941.

25. Antunes P, Ginj M, Walter MA, Chen J, Reubi JC, Maecke HR. Influence of different spacers on the biological profile of a DOTA-somatostatin analogue. Bioconjug Chem. 2007;18:84-92.

26. Garcia Garayoa E, Schweinsberg C, Maes V, et al. Influence of the molecular charge on the biodistribution of bombesin analogues labeled with the [ ${ }^{99 \mathrm{~m}} \mathrm{Tc}$ (CO)3]-core. Bioconjug Chem. 2008;19:2409-2416.

27. Gotthardt M, van Eerd-Vismale J, Oyen WJ, et al. Indication for different mechanisms of kidney uptake of radiolabeled peptides. J Nucl Med. 2007; 48:596-601.

28. Verwijnen SM, Krenning EP, Valkema R, Huijmans JG, de Jong M. Oral versus intravenous administration of lysine: equal effectiveness in reduction of renal uptake of [ ${ }^{111}$ In-DTPA] octreotide. J Nucl Med. 2005;46:2057-2060.

29. Ginj M, Zhang H, Waser B, et al. Radiolabeled somatostatin receptor antagonists are preferable to agonists for in vivo peptide receptor targeting of tumors. Proc Natl Acad Sci USA. 2006;103:16436-16441. 